\title{
ROSA CHACEL Y SUS POSIBILIDADES
}

\author{
ANA BANDE BANDE \\ Universidade de Vigo \\ ulises.ana@gmail.com
}

RESUMEN: El presente artículo constituye una puesta al día del estado de la investigación sobre la obra de Rosa Chacel tomando como base las tesis doctorales que se han realizado sobre su obra. La mujer y sus posibilidades fue el extraordinario título que Rosa Chacel eligió para su conferencia en el Ateneo en 1921, un texto que marcaría el origen de una vida dedicada a la reflexión más rigurosa y profunda. Todo lo suyo es inaudito, pero seguimos permitiéndonos ignorarla, como si todo fuera, efectivamente, normal. Ante la inquebrantable voluntad creativa no existe mayor absurdo que el olvido deliberado, así que, como ella misma hizo a lo largo de su larga vida, hay que seguir insistiendo. El presente artículo constituye una puesta al día del estado de la investigación en torno a esta autora, que, en cada lectura, nos descubre, efectivamente, nuevas posibilidades.

PALABRAS CLAVE: Rosa Chacel, feminismo, exilio, bildungsroman, autobiografía, memoria, confesión, erotismo, homosexualidad, guerra civil, antifascismo, Ortega, poesía, ciudad, tesis doctorales. 


\section{ROSA CHACEL AND HER POSSIBILITIES}

ABSTRACT: This article provides an update on the latest research on the corpus of Rosa Chacel, based on a discussion of PhD theses on her work. La mujer y sus posibilidades (A Woman's Possibilities) is the extraordinary title that Rosa Chacel chose for the lecture she delivered at the Ateneo in 1921. The text marks the beginning of a life devoted to rigorous and in-depth reflection. Everything about Chacel is exceptional and yet she has been cast into oblivion, perhaps because our world does not allow for exceptionalities. Faced with her unshakeable creative will, our deliberate forgetfulness proves totally absurd. Thus, just as she herself did, one should never give up, one must insist. In this spirit, this essay aspires to offer an assessment of the multifaceted research on Chacel to date, with the intention of re-discovering new reading possibilities.

KEYWORDS: Rosa Chacel, feminism, exile, bildungsroman, autobiography, erotism, civil war, doctoral dissertations.
Lo único deseable es que la mujer llegue a lograr claridad para consigo misma sobre lo que quiere o no quiere, puede o no puede, debe o no debe tolerar. Por creerlo así, mi acento respecto a la mujer adoptará a veces un tono poco simpático que, claro está, sólo será la expresión de una más difícil e inédita simpatía.

Hubo mujeres, estaban allí, yo las conocí, sus familias las encerraron en manicomios, se las sometía a tratamiento por eletrochoque. En los años 50 si eras hombre apenas podías ser un rebelde, pero si eras una mujer tu familia te encerraba. Hubo casos, yo las conocí. Algún día alguien escribirá sobre ellas. (Respuesta de Gregory Corso cuando a razón de una conferencia celebrada en 1994 le preguntaron por qué no hubo mujeres en la generación beat. (Mari Pegrum, 2015: 8)

$\mathrm{E}$

n estas dos citas creo que queda perfectamente identificado el objetivo y los contenidos que me interesan destacar en este artículo. Las declaraciones y reflexiones de Rosa Chacel en relación con el tema de la mujer invitan tanto a un rechazo tajante - si sucumbimos a la vehemencia de esas declaraciones deliberadamente provocativas de la autora ${ }^{2}-$, como a un deseo de adentrarse con una curiosidad infinita en su obra. Después de leer muchos de sus textos y comentarios

${ }^{1}$ Cita tomada de Rosa Chacel, Saturnal (Chacel, 1989: 69-70).

${ }^{2}$ Chacel nos avisa constantemente de la prevención que debemos adoptar frente a sus "estridentes" declaraciones: "pero mi simpatía yo sólo sé manifestarla a mi modo y tal vez resulte algo estridente porque mi modo personal consiste en poner los puntos sobre las íes. Esta afirmación ya puede parecer la primera estridencia, pero no es lo que parece" (Documento inédito consultado en el Archivo de la autora depositado en la Fundación Jorge Guillén [RCH 13/027]). 
no tengo dudas acerca de su actitud en este tema ni de su valentía a la hora de afrontarlo, porque, para compartir el deleite de sus reflexiones y sobre todo de sus indecisiones, no hay otro camino, efectivamente, que el del esfuerzo que la autora exige para comprender esa más difícil e inédita simpatía ${ }^{3}$ Y lo encuentro justísimo dado que Chacel ha jugado a la contra, sola y además sin esconder sus pensamientos más políticamente incorrectos. La satisfactoria ausencia en nuestra autora de la debilidad de carácter que suele esconderse detrás de la llamada corrección política, le ha permitido articular unos textos que, de haber sido reconocidos en otro tiempo, nos hubieran procurado unos estándares de progreso para la mujer bien distintos.

\section{La vida de "una señorita de Valladolid"}

No puedo presentar a Rosa Chacel sin sufrir el enorme desasosiego que produce tratar de "rescatar", una vez más, a una figura tan insustituible como marginada en la literatura y la cultura española. Pero la desazón va unida al agradecimiento a la inquebrantable labor de recuperación que de su obra y de su pensamiento - con resultados bien poco proporcionados a su esfuerzo - ya se han realizado, pues no podemos dejar de mencionar los imprescindibles trabajos que han hecho posible que, a pesar del exilio, la miopía intelectual, la deliberada ignorancia (la más execrable) y el desinterés por todo el universo literario, filosófico y poético aportado por esta "señorita de Valladolid", a decir de Neruda, los textos de Chacel estén hoy bien editados y a disposición para su lectura e investigación ${ }^{4}$. aluden a ese esfuerzo requerido para adentrarse en la obra chaceliana: Lo cie que intentar comprender la obra de esta mujer implica, al menos, un gran esfuerzo, que la única manera de aproximarse a ella es rastrear en cada uno de los textos que escribió, (novelas, cuentos, poemas, diarios, autobiografía y biografía, memorias, artículos y comentarios) su meditado proyecto "poético".

${ }^{4}$ A este respecto me gustaría señalar el celo con que la Fundación Jorge Guillén custodia el archivo de la autora y la amable predisposición de todo su personal para poner este acervo documental al servicio de la investigación. El tratamiento técnico de los archivos literarios en nuestro país está por resolver mientras no se definan las
Rosa Chacel nació en Valladolid en el año 1898. Esta fecha la vincula a un período de enorme productividad en España, pues supone la emergencia de la Generación del 27, protagonista de las innovaciones estéticas que, siguiendo a Joyce o a Proust, se propondría la definitiva incorporación de nuestra narrativa a la literatura contemporánea. Chacel fue la única novelista del grupo y sin duda la más inconformista.

El traslado a Madrid en 1908, al Barrio de Maravillas, va a dejar profundísima huella en su vida y su obra. Barrio de Maravillas es, precisamente, el título de la primera parte de su trilogía autobiográfica, de la que también formaron parte Acrópolis y Ciencias Naturales. A los doce años asiste a la Escuela de Artes y Oficios y, posteriormente, con su ingreso en la Escuela de Bellas Artes de San Fernando, donde estudia escultura, entra en contacto con el círculo cultural madrileño en 1915 y conoce a Timoteo Pérez Rubio y a otros artistas jóvenes, siendo alumna además de Valle Inclán y Julio Romero de Torres.

En el Ateneo de Madrid, se atracaba de filosofía, según sus palabras, y acabó convirtiéndose en una de las intelectuales más cultas de su generación, como lo atestigua el comentario que según Zambrano le habían hecho sobre ella:

\begin{abstract}
María, he conocido y oído en Madrid a una muchacha, tan joven como tú, hablar de Nietzsche en el Ateneo de Madrid. Ya no eres la única, ella se te ha adelantado. Tiene talento, belleza y el hado del genio en su frente. Yo temblé de alegría y un poco angustiada ${ }^{5}$.
\end{abstract}

políticas de conservación a seguir con este tipo de fondos, tradicionalmente objeto de "disputa" entre archivos y bibliotecas. A mi modo de ver, los textos literarios - trátese se originales o de copias - constituyen el corpus básico para el trabajo filológico, como demuestra Carmen Morán (2015) en sus "calas" en el Archivo de Rosa Chacel, especialmente desde la vigencia de la crítica genética basada, precisamente, en la materialidad de los textos.

5 Testimonio incluido en "Rosa”, publicado en Un Ángel Más, 3-4, Valladolid, 1988, p.12 (Pardo, 2001: 111).

UNED. REI, 4 (2016), pp. 153-194

ISSN 2340-9029 
En esta época se relaciona con los intelectuales del momento y asiste a las tertulias que permitían el acceso a mujeres: La Cacharrería del Ateneo y la de la Granja del Henar. Es un período de ebullición cultural en el que ella participa activamente, como lo demuestra su colaboración en la revista Ultra ${ }^{6}$

En 1922 se casa con Timoteo Pérez Rubio y viajan a Roma gracias a una beca obtenida por su marido para estudiar en la Academia Española en aquella ciudad. En Roma hay que situar el punto de partida de su vida profesional, puesto que allí es donde lee a Ortega, Joyce y Freud, cuyo resultado se plasmaría en su primera y decisiva novela Estación. Ida y Vuelta. En 1927 regresa a Madrid, se convierte en discípula de Ortega y colabora con la Revista de Occidente y La Gaceta Literaria, las revistas más emblemáticas de la vanguardia. $\mathrm{Su}$ segunda obra fue la biografía de Teresa Mancha, un encargo que le hizo Ortega para su colección Vidas españolas e hispanoamericanas del siglo XIX. Elizabeth Scarlett (1997: 112) se pregunta muy oportunamente si Ortega era consciente de que le estaba pidiendo a una escritora ferozmente independiente que rescatara a una mujer olvidada cuyo único aspecto extraordinario era el vínculo amoroso con el poeta y que aparentemente la había llevado a la destrucción.

El nacimiento de la Segunda República influyó en la vida de todos los intelectuales, puesto que, como Chacel reconocía, todos hacían cosas que no habían hecho antes, si bien la escritora siempre se mantuvo al margen de la acción política directa. Entre esas cosas que no se habían hecho antes se incluiría su flamante ensayo Esquema de los problemas prácticos y actuales del amor, en donde, arropándose estratégicamente en la tesis de Scheler, refutó las ideas misóginas de Ortega y sus coetáneos.

En 1933 se establece en Berlín durante seis meses, en donde, aparte de disfrutar de una gozosa experiencia literaria con Alberti y Teresa León, asiste a las primeras manifestaciones públicas del ascen-

${ }^{6}$ En el no 23 publicó su relato "Las ciudades": http://hemerotecadigital.bne.es/results. $v m ? q=$ parent $\% 3 A 0003796070 \& s=20 \&$ lang=es [consulta 21/06/2016] so del nazismo. De vuelta a Madrid, demuestra su identificación con la causa del Frente Popular adhiriéndose a su programa y, ya en los primeros meses de la guerra, firmando el Manifiesto Fundacional de la Alianza de Intelectuales Antifascistas, trabajando como enfermera y sobre todo colaborando con las principales publicaciones republicanas, El Mono Azul y Hora de España. Cuando se desencadena la contienda con todo su rigor emigra con su familia a América, alternando allí su residencia entre Río de Janeiro y Buenos Aires. Durante la década de los cuarenta "sobrevive" económica e intelectualmente gracias a sus colaboraciones en La Nación y las revistas Sur, Realidad y Anales de Buenos Aires y a su labor como traductora7. Son años muy duros para la autora, en los que su extraordinaria capacidad literaria sobrevive en sus Diarios hasta que consigue, tras diez años de arduo trabajo, finalizar la que será su obra cumbre, La Sinrazón. En 1959, gracias a una beca que le concede la Fundación Guggenheim, se traslada a Nueva York, en donde reanuda sus reflexiones sobre la cuestión de la mujer, que había iniciado treinta años atrás y que culmina en su grandioso ensayo Saturnal. Finalizada esa etapa en 1961, realiza una serie de visitas a España y su obra empieza a ser conocida en la década de los sesenta, aunque muy tímidamente. El retorno definitivo a su país se produce en 1973, y comienza una época muy fecunda en la que se publican Novelas antes de tiempo, Versos prohibidos, Timoteo Pérez Rubio y sus retratos del jardín, Los títulos, Diarios, Acrópolis, Ciencias Naturales, Rabañaduras, La literatura es Secreto y, por fin, la edición de su Obra Completa. Rosa Chacel comienza entonces a recibir reconocimientos importantes, como el doctorado Honoris Causa por la Universidad de Valladolid o el Premio Nacional de las Letras Españolas, entre otros.

7 Algunas de sus traducciones: La dama no es para la hoguera y Venus observada, de Christopher Fry; Reunión de familia, de T. S. Elliot; Herodiade, de Stéphane Mallarmé; La peste, de Albert Camus; Libertad o muerte, de Nikos Kazantzakis; Fedra $y$ otras tragedias, de Jean Racine, Animales desnaturalizados, de Vercors; Museo de Cámara, de Valmir Ayala.

UNED. REI, 4 (2016), pp. 153-194

ISSN 2340-9029 
El título del presente trabajo responde no sólo a lo que tiene de homenaje debido a sus resonancias evocadoras, al remitir al de aquella primera conferencia de la autora en el Ateneo de Madrid en $1921^{\circ}$, sino, sobre todo a la apremiante necesidad de compartir lo que considero una obra excepcional y lamentablemente todavía relegada a los márgenes de los estudios académicos.

Las continuas reflexiones sobre el tema de la mujer a lo largo de la obra de Chacel constituyen un yacimiento inagotable e imprescindible para la investigación sobre las relaciones de género. Además, fue objeto de sus principales preocupaciones desde el comienzo de su actividad intelectual (tenía sólo 23 años cuando impartió la conferencia mencionada) hasta 1994 en que fallece con 96 años; Volviendo al punto de partida (1964), La Sinrazón $n^{9}$ (1968), Saturnal (1972), La mujer en galeras (1975) y La mujer en el siglo XX (1980) están entre los más relevantes.

\section{Rosa Chacel ante la crítica}

Es a Ana María Moix a quien debemos en primer lugar este reconocimiento. Fue el "atrevimiento" de aquella chica de 18 años, cautivada por la lectura de su obra, el que la decidió a ponerse en contacto con la autora e iniciar así la primera labor de "recuperación", de la que ha quedado como testimonio un hermoso y productivo inter-

${ }^{8}$ Se trata de la conferencia sobre el tema "La mujer y sus posibilidades", impartida en el Ateneo de Madrid en diciembre de 1921, hoy lamentablemente perdida. Podemos consultar las notas de prensa sobre la misma en la Hemeroteca Digital de la Biblioteca Nacional: La Época. 28/12/1921, 25.584, p. 3 [http://hemerotecadigital.bne.es/issue. vm?id=0000958218\&page=3\&search=mujer+posibilidades+chacel\&lang=es], El Globo. $28 / 12 / 1921,15$, p. 2

[http://hemerotecadigital.bne.es/issue.vm?id=0001489330\&page $=2 \&$ search $=$ mujer + posib ilidades+chacel\&lang=es]

9 Ana Gómez Pérez (2014: 22) señala que La Sinrazón, en la que Herminia, uno de los personajes principales, escribe una obra de teatro en la que establece un paralelo entre el mito de la Orestíada y la evolución de las tensiones entre hombres y mujeres durante la época contemporánea, debe ser considerada parte del corpus de la autora sobre la mujer. cambio epistolar (Rodríguez-Fischer, 1998). Ana María Moix, junto con Pere Gimferrer y Guillermo Carnero (el "trébol poético", como los llamaba Chacel) fueron los primeros responsables de la recuperación de la obra de la autora, exiliada, en aquel entonces, de España. Pero, por supuesto, habrían de seguir muchos otros indispensables para el reconocimiento de Rosa Chacel, entre los que destacamos a Carol Maier, Julián Marías, Ana Rodríguez Fischer, Kathleen Glenn, Roberta Johnson, Rafael Conte, Clara Janés, Shirley Mangini, Susan Kirpatrick, Asunción Mateo, Alberto Porlán, Antonio Piedra, Raquel Asún, Aurora Egido, Pilar Gómez Bedate, Ángel Crespo o Laura Freixas y, por supuesto, todas las investigadoras que reseñamos en el presente artículo

Desde que en 1986 Ana Rodríguez-Fischer presentara su monumental tesis, los trabajos de investigación se han multiplicado. Para conocer el estado de la investigación sobre la escritora hemos seleccionado tanto los trabajos que se centran en la obra de Chacel, como este de Rodríguez-Fischer, pero también los de investigadoras que la han estudiado siguiendo una metodología comparatista relacionándola con narraciones de otras escritoras.

La tesis de Ana Rodríguez Fischer sobre Chace ${ }^{10}$, aparte de su monumentalidad, tiene el mérito de constituir el punto de partida de un interés académico por la autora que, a partir de 1986, año de su publicación, no deja de aumentar. Pero la relevancia de este trabajo se justifica no sólo por lo que tiene de inaugural en la visualización de la obra de la autora, sino por la exhaustividad en el análisis de su obra "total", de forma que aún hoy, treinta años después de su publicación, su consulta es obligada y fructífera para cualquier investigación sobre la escritora. Además, al haber sido realizado en vida de la autora, ha podido contar con su directa colaboración. De la calidad del trabajo de Ana Rodríguez ha dejado constancia Chacel:

${ }^{10}$ Ana Rodríguez-Fischer es, a día de hoy, la mayor especialista en la vida y obra de Rosa Chacel. Aparte de su tesis, es responsable de numerosos prólogos y estudios de la obra de Chacel y también ha sido editora de la mayor parte de su Obra Completa. 
Apareció Ana Rodríguez con su tesis extraordinaria. Es increíble lo que esta criatura está poniendo ahí: ¡qué inteligencia, que profundidad y qué capacidad de trabajo! (Chacel, 2004: 889)

He tardado mucho en ver las dimensiones de esa tesis. Siempre me pareció magnífica pero ahora me parece algo desmesurado. Su perfección es tal como estudio, como valor crítico, como sutileza de percepción, interpretación, etc., que cuesta trabajo creer que se obtenga - quiero decir que yo obtenga - una cosa semejante. (Chacel, 2004: 922)

La investigadora francesa Daniéle Miglos (1990) también realizó su trabajo en vida de la autora y también contó con su activa colaboración. Su trabajo es resultado de su indagación en la importancia de la literatura centrada en el "yo" como reivindicación de la subjetividad, concretándose en la importancia de la voz narrativa a lo largo de los diarios íntimos de Chacel, en los que se revelan sus proyectos, sus relaciones con otros textos y lugares y sobre todo los procesos de génesis de su obra a través de los que se puedan intuir los tesoros escondidos en lo explícito y en los silencios de la autobiografía. Miglos pudo penetrar en el taller de la autora, cuya colaboración, como ella misma reconoce en sus diarios, tenía mucho que ver con su esperanza de ser traducida y conocida en el país vecino:

[...] llamó por teléfono Daniéle Miglos [...] tengo un interés enorme en conocer a esta criatura. Pocas veces -en estos tiempos- mi interés sobrepasa todo lo que hay $-\mathrm{y}$ hay mucho- de interesado porque es cierto que obtener mi aparición en Francia significaría meter un gol de lujo [...] . (Chacel, 2004: 951)

Algunos trabajos en torno a la obra de Chacel parecen contagiarse, afortunadamente, de su espíritu rebelde, presentando con una apasionada rigurosidad, a la altura de la intrepidez chaceliana, unas conclusiones ciertamente interesantes. Es el caso del de María A. Martínez Carbajo (2001) cuyo arriesgado estudio apunta precisamente a ese atrevimiento de la escritora en la configuración de personajes altamente problemáticos que pueblan su obra:

Ante tal absorción [del conocimiento] su mundo, ya creativo por sí mismo, se llenó de criaturas que clamaban su libertad. Y pasó lo que tuvo que pasar, que los más rebeldes, a saber, adúlteras, niñas precoces, pupilas enamoradas de sus maestros, amantes desvergonzados, hombres impotentes con ansias de deseo, y demás individuos de "mala calaña" (el subrayado es de la autora) dieron un golpe de estado literario que, hay que apuntar, fue abortado, no sin que este grupo de revolucionarios se escapara a través de un compartimento secreto llamado escritura (Martínez Carbajo 2001: 225).

Martínez Carbajo señala que sus personajes son, como la propia Chacel, seres marginales, pero precisamente lo son por su no admisión de los principios establecidos. Son, según ella, "seres infelices e incompletos que, incluso en momentos de máxima felicidad, no llegan a disfrutar de ésta plenamente debido a su constante crisis existencial" (2001:228). La propuesta de Chacel a la fuerza tendría que haber provocado escándalo e incredulidad en una sociedad literaria española tan tradicional, lo que causaría en la autora un sentimiento de alienación.

Carmen Morán (2006) ${ }^{11}$, en una aportación generalista a la obra chaceliana, profundiza, afortunadamente, en el estudio de su producción ensayística, hasta el momento insuficientemente atendida y de gran interés por la invisibilización a que estuvieron sometidas las reflexiones teóricas de las mujeres en general en el primer tercio del pasado siglo, y de Rosa Chacel en particular, a pesar de haber sido casi la única que dispuso de un espacio privilegiado en las publicaciones vanguardistas intelectualmente más exigentes de la época. De modo que no podemos disimular el entusiasmo que nos produce la lectura de las seiscientas y necesarias páginas de este trabajo. Morán

${ }^{11}$ Agradezco enormemente a Carmen Morán el envío de su tesis hasta ahora inédita. 
es de las pocas investigadoras que reparó en la importancia del que tenemos por el ensayo más inteligente sobre la situación de la mujer ${ }^{12}$ por lo que tiene de anticipador de un discurso que lamentablemente no tuvo continuidad en nuestro país. También se detiene en el estudio de uno de sus textos más "calientes" y provocadores, su Comentario tardío sobre Simone de Beauvoir y la continuación del discurso chaceliano en torno al mismo tema en el controvertido y reelaboradísimo ensayo Saturnal. Completa su estudio con la revisión de las obras ¿de ficción? en donde Rosa Chacel implementa todas esas ideas ofreciéndonos una revisión global de la crítica sobre las mismas y aportando una visión sugerente y completamente incitante para su relectura.

Como hemos apuntado ya, la obra chaceliana se halla impregnada de su preocupación por el tema de la mujer, de modo que no resulta extraño que la mayor parte de los trabajos sobre su obra lo hagan bajo los presupuestos de la crítica feminista, tan fecunda, por otra parte, como metodología para sus análisis. Elizabeth Scarlett, una de las voces imprescindibles en la investigación de la obra chaceliana, inaugura con su trabajo esta perspectiva en la interpretación de los textos de la escritora. Scarlett (1991) incorpora las teorías contemporáneas de Barthes y Foucault a su estudio sobre la importancia de la representación del cuerpo femenino a través del análisis de las obras de Emilia Pardo Bazán, Rosa Chacel y Mercé Rodoreda. Las claves feministas de Kristeva y Luce Irigaray contribuyen a su interpretación de las primeras obras de la escritora, entrando también a analizar su relación con la vanguardia española anterior a la guerra civil. Analiza la importancia de los diálogos textuales que mantiene Chacel con Freud, Joyce y Ortega. Scarlett ha realizado posteriormente importantes contribuciones al estudio de una escritora que se presenta como problemática por sus alternativas propuestas a los modelos tradicionales de feminidad y masculinidad:

\footnotetext{
${ }^{12}$ Nos referimos al ensayo que publicó Rosa Chacel en 1931 en la Revista de Occidente: "Esquema sobre los problemas actuales del amor".
} UNED. REI, 4 (2016), pp. 153-194

Rosa sobrevivió gracias a su durísimo individualismo, lo cual no le permitía agregarse al grupo de las masas femeninas. Sin embargo, la negación misma del significado de su propio género sexual, la lucha que emprendió para alcanzar la igualdad con los mejores artistas a pesar del predominio masculino en las nuevas vanguardias y sin recurrir explícitamente al discurso femenino, no deja de tener fuertes huellas en su obra. (Scarlett, 1997: 110)

Lori Beth Pattison (1993) avanza en el esfuerzo crítico que trata de asegurar para Chacel un lugar en el canon literario español. Con su análisis de las implicaciones ideológicas y las preocupaciones estéticas de Chacel en sus cuatro primeras novelas (Estación. Ida y Vuelta, 1930; Teresa, 1941; Memorias de Leticia Valle, 1945; y La Sinrazón, 1960), se aleja de las interpretaciones tradicionales de lo autobiográfico en estas obras para explorar las implicaciones del feminismo en la estética chaceliana. En estos cuatro relatos del "yo", los protagonistas toman conciencia de sí mismos a través del acto de narrar, destacando que el género de los personajes no sólo influye, sino que determina el género de los textos que construyen sobre sí mismos, siendo por lo tanto productores y productos de sí mismos. Otro interesante aspecto que inaugura este estudio y que tendrá afortunadas consecuencias en investigaciones más recientes es el interés que observa en la superposición de la voz autorial sobre la voz narrativa como estrategia para "socavar" los estereotipos tradicionales de género. A día de hoy, la crítica ha visto con suficiente claridad el uso que hace Chacel de la ficción como medio para explorar la relación entre géneros. Esta metodología la justifica Pattison al constatar la renuencia que había a hablar del trabajo de la escritora dentro de un marco feminista y la tendencia a ignorar la distinción entre autor y narrador en sus novelas. Su trabajo es pionero en este sentido, ya que por primera vez resalta la importancia del hecho de que sus personajes principales experimentan el deseo de autorizarse para narrar su propia vida, para escribir su propia novela. Si tenemos presente el enorme esfuerzo y sufrimiento que supuso para Rosa Chacel el hacer- 
se con su propia voz y el precio que pagó por ello, el punto de partida de este estudio no puede estar mejor justificado.

Los resultados de la investigación de Reyes Lázaro (1995), a mi modo de ver, constituyen un hito en la investigación chaceliana desde el feminismo. Lo más acertado de su propuesta nos parece el análisis de la relación que establece la escritora con sus padres literarios. Ya conocemos la tendencia conservadora que caracterizó, en lo que al género se refiere y concretamente en la consideración que tenían de la capacidad creadora de la mujer, a los dos grupos literarios - dominados por hombres - con los que se afilia Chacel literariamente. Lázaro ofrece un recuento de los maestros de la autora - siguiendo la teoría freudiana de Harold Bloom en lo relativo a la ansiedad de la influencia que afecta a las escritoras - como una cadena de padres misóginos. La ansiedad con que Chacel tuvo que abordar la obligada transgresión o reversión de las teorías de sus mentores se llevó a cabo a través de una estrategia muy eficaz: la subversión. La investigadora dedica mucho espacio a ofrecer una explicación de lo que quizás sea el aspecto más delicado y problemático de la obra chaceliana: su relación con las cuestiones de género. En el proceso de filiación con el patriarcado, Chacel tiene que reinterpretar la visión que sus mentores tienen de lo femenino, la cual cuestiona precisamente la legitimidad que la escritora pretende adquirir. Preguntarse por la salida de esa encrucijada es, precisamente, creo, empezar a entender la obra de la escritora. Buscar en sus opciones y sus respuestas una justificación a su problemática situación es un paso ineludible para comprender primero y valorar después sus propuestas como decisiones insobornablemente lúcidas, necesarias y, diría, modernas. Y creo que con este trabajo Lázaro ayuda a entrar decididamente en una obra magistral pero oculta por los enormes prejuicios que, incluso desde el feminismo, impidieron un tratamiento respetable de la narrativa de la autora. Esas respuestas están en las estrategias subversivas que Reyes Lázaro define como tretas y malinterpretaciones deliberadas que Chacel utiliza para autoafirmarse como artista, concretamente como mujer artista. Con esta estrategia, la autora habría conseguido autocrearse a través de sus mentores, pero pagando un elevado precio en forma de autonegación, angustia y hasta parálisis creativa. Un ejemplo de todo ello sería el personaje de Leticia Valle, puesto que representa a la perfección la subversión que claramente realiza del tradicional relato de seducción al revertir los papeles completamente y presentar como parte activa de la seducción no sólo a una mujer, sino a una niña, que es, además, dueña de su relato al haberse arropado con el poder de su propia voz mediante la escritura de sus memorias y presentar al hombre como seducido y derrotado. Esta interpretación tan ajustada de uno de los personajes más problemáticos de la obra chaceliana nos hace valorar especialmente este trabajo (Lázaro, 2002). Shirley Mangini, una de las máximas conocedoras de la obra chaceliana, también observa que:

Astutamente, Reyes Lázaro, Leticia (y por ende Rosa Chacel, señala Lázaro) opta por lo que Judith Butler llama la "introversión", que consiste en la habilidad de transformar, desde la interioridad, un sistema (patriarcal, en este caso) en una versión propia. (Mangini, 2006: 176)

M. Soledad Fernández Utrera (1995) coloca también a Chacel dentro de la línea teórica del feminismo moderadamente progresista y totalmente inmersa, como sus compañeros de viaje vanguardista, en el programa ideológico del nuevo liberalismo español. Propone un análisis de su obra en contraste con la escritura de vanguardia masculina, resaltando además la importancia del componente racional y reflexivo de la escritura y la identidad femenina. En este sentido, la novela de Chacel sería igual que la de Joyce, el retrato de un joven artista. Es muy relevante la originalidad de su análisis, en el que a la visión narcisista y concéntrica, el "yo", opone la observación excéntrica. Para explicarlo, la autora recurre a un eficiente ejemplo de visión de estereoscopio a través de la cual incorpora la técnica fotográfica y de artilugios técnicos, muy de la época, al análisis del yo narrador.

A través de una lúcida reflexión sobre las narraciones de cuatro escritoras hispanas como Teresa Parra, Rosa Chacel, Alba Lucía Ángel y Gloria Anzaldúa, Elena Grau-Llevería (1997) demuestra también cómo, a la luz de la teoría de género, el postmodernismo y el 
feminismo, las mujeres han sido capaces de reformular el concepto hegemónico de historia. La importancia de la voz de la mujer como material histórico se consigue también mediante la recuperación de los personajes literarios femeninos, pues reflejan un modo diferente de entender los acontecimientos públicos y privados porque los han vivido desde una posición distinta del hombre. La propuesta de Elena Grau es el análisis del tipo de representación de las mujeres y de la función de la escritura en la construcción del sujeto y sus estrategias para crear una identidad posible. Así, la apropiación del espacio personal y del modo privado de enfrentarse al mundo pueden convertirse en una plataforma subversiva de relectura histórica, de reversión de los discursos generadores de poder. Leticia Valle vuelve a ser el personaje paradigmático para ejemplificar la eficacia, en el sentido de esa búsqueda, de una historia propia contada por una niña que se muestra plenamente consciente de la "distancia" que la separa del mundo del conocimiento. Al estar este conocimiento monopolizado por lo masculino, su abordaje a la fuerza toma forma de una seducción. Y dado que a la mujer también le está vetada la posibilidad de una posesión consecuencia de su pasión, el desenlace será igualmente interpretado desde el canónico discurso hegemónico como una seducción convencional. De este modo, la entrada de la mujer en ese mundo (en el despacho de don Daniel, el profesor "seducido") es interpretada como una seducción sexual en que la víctima es la mujer. Porque nadie - en el entorno de Leticia - se imagina la posibilidad de que haya sido ella la seductora. Sin embargo, es precisamente este deliberado deseo de venganza que acumula Leticia por verse constantemente relegada del mundo del conocimiento lo que la impulsará a tomar la palabra para hacerse con su propia voz y desencadenar la tragedia. La lectura que hace Grau-Llevería del personaje es ya mucho más elaborada, quizá como consecuencia de una investigación pretérita que había incorporado nuevos y originales presupuestos en la interpretación de los textos de Chacel. A este respecto, creo que las conclusiones del trabajo de Reyes Lázaro están muy presentes en todas las investigaciones.
Lidia León-Blázquez (2011) hace también una aportación a la investigación sobre Rosa Chacel desde el ámbito de los estudios feministas y de género, pero también de teoría estética y literaria y de historia universal. Lo original de su contribución es el punto de vista de acercamiento a la escritora mediante el binomio metafórico de lo textil-textual, recurrentemente empleado por Chacel para expresar el difícil acceso de la mujer a los círculos intelectuales vanguardistas. A la investigadora le interesan precisamente los textos que surgen del sentimiento de rabia de la autora frente al ninguneo sufrido por ser una escritora "femenina", a pesar de todos los esfuerzos que invirtió para demostrar que era un "escritor", de los pies a la cabeza. Asimismo, le parece paradigmática, la anticipación que suponen los textos de Chacel al debate feminista y de gran parte de la discusión teórica literaria del siglo XX. Las obras más interesantes para demostrar esas tesis, esos textos producto por la rabia, serían, y coincido plenamente con su elección, las novelas Teresa, Memorias de Leticia Valle, el cuento "Ofrenda a una virgen loca" y los dos primeros libros de su trilogía final La Escuela de Platón, Barrio de Maravillas y Acrópolis. La más emblemática en este sentido sería también Memorias de Leticia Valle, lo cual no nos sorprende, pues somos plenamente conscientes de las innumerables interpretaciones que la han hecho objeto de tantas investigaciones ${ }^{13}$. En esa novela, Chacel emplea el triple problema del género - textil, literario y sexual- para referirse a lo femenino como una instancia culturalmente construida y para desarrollar planteamientos estéticos que sólo empezarían a tantearse en el mundo académico a partir de los años sesenta con la deconstrucción.

La crítica feminista acredita su eficacia y diversidad a la hora de interpretar la obra de nuestra escritora en el trabajo de Julie Mann Lind (2013). Se centra en el discurso feminista en textos escritos por mujeres españolas que usan el hambre y el apetito como tropos literarios después de los años de la escasez de la posguerra. La metáfora ad-

${ }_{13}$ Aparte de los capítulos específicos dedicados a este personaje en los trabajos de investigación que venimos estudiando, la investigadora Nilma Machado Carvalho dedica la integridad de su tesis al estudio de Leticia Valle (Carvalho, 2009).

UNED. REI, 4 (2016), pp. 153-194

ISSN 2340-9029 
quiere todo el sentido porque si por una parte la comida, la cocina, es el espacio que mejor refleja ese papel subsidiario de la mujer, también invita a reflexionar sobre los anhelos y el hambre de la propia mujer. En los textos de Zambrano y Chacel, descubre las tensiones que se forman cuando las mujeres luchan por dar alimentación artística e intelectual a sus cuerpos. Este planteamiento resulta especialmente relevante, pues es precisamente una constante en toda la vida y obra de Chacel ese apetito voraz de conocimiento, al que ella se refiere en numerosas ocasiones como un eros insaciable y cuyo trasunto más perfecto sería-otra vez- Leticia Valle, cuyo apetito es su razón de ser y el motor de toda la narración.

De la relevancia de la obra chaceliana Estación. Ida y vuelta, como el mejor ejemplo de novela hispánica vanguadista, resultado de la asimilación de las nuevas propuestas literarias introducidas por Ortega y Joyce, es una buena muestra el conjunto de investigaciones que tomaron esta obra como tema central.

Tatjana Gajic (2001) reflexiona sobre las condiciones socioculturales que exigían una reforma de la nación a través de la práctica intelectual en la España anterior a la Guerra Civil y en la que el proyecto filosófico de Ortega y Gasset se erigió como el modelo a seguir. En este proyecto, correspondería a la literatura la creación del horizonte simbólico necesario para la reforma nacional, que se centraría en la noción de autoformación que justamente constituye el centro de la práctica filosófica-literaria de María Zambrano y Rosa Chacel. Se analizan las características específicas de la modernidad española, la peculiar posición de España dentro de Europa, en la que sobresale la combinación de un enfoque modernizador con una defensa bastante reaccionaria de la tradición nacional. A la ausencia de una tradición institucionalizada del pensamiento moderno en España haría frente precisamente Chacel con su crítica a la tradición literaria española y su énfasis en el valor de "persona" y la experiencia personal. Nuestra autora aportaría en este necesario proyecto de revisión -lamentablemente zanjado por la guerra civil - una serie de innovadoras y complejas novelas que investigan el aspecto cotidiano de la historia a través de una curiosa combinación de confesión y auto-ocultamiento que, a la postre, participa del mismo "fracaso político" que afectó también a Ortega y Zambrano. En el primero, tal fracaso sería el de su proyecto europeísta elitista y en el de Chacel se encontraría en el deslizamiento de la autora hacia la defensa de un eros individualista.

Teresa Kennedy (1995) propone una traducción al inglés de la obra Estación. Ida y Vuelta en la que incorpora un estudio interpretativo del texto que analiza la puesta en práctica que hizo Chacel de las teorías sobre el arte y la ficción que estableció Ortega. La investigadora observa un subtexto detrás de la fachada filosófica de la obra, en el que se traducen las dificultades con las que se encontraba una mujer como autora literaria en la España de principios del siglo XX.

También Sheila Marie Risbud (1995: 76) considera Estación. Ida y Vuelta como el "ejemplo más logrado del alma española aventurada en la doctrina de Ortega" con el fin de "destacar a una escritora que supo desarrollar un estilo propio a pesar de encontrarse en un mundo literario en el cual era prácticamente obligatorio seguir el canon de Ortega para tener éxito". Y la investigadora sueca Sofia Nylén (2014) analiza esta obra de Chacel en comparación con Astarté, de la escritora Karin Boye, desde la perspectiva de la crítica feminista y del análisis del discurso, como ejemplos de dos obras olvidadas por el canon occidental de la literatura del siglo XX y que, gracias a la hermenéutica postestructurlista, feminista o de la desconstrucción, han demostrado su valor como formas experimentales de gran importancia en el vibrante debate académico sobre la construcción de la identidad y la concepción del género humano.

Un estudio de la autobiografía literaria en nuestro país tiene que contar forzosamente con la obra de Rosa Chacel, puesto que su obsesión por el "yo" hace que toda su obra esté impregnada de autobiografismo. Chacel hizo de su vida prácticamente un ejercicio de memoria, de manera que es casi imposible dibujar la línea que separa la vida de la escritura de la autora. Su obsesión memorística se plasmó tanto en textos típicamente autobiográficos como diarios, memorias, confesiones - por lo que tiene precisamente de pulsión de escritura 
motivada por el sentimiento de culpa - como en sus novelas, cuya lectura siempre está condicionada por evidentes paralelismos con su vida y cuyo efecto ella se encarga de reforzar con tajantes declaraciones ${ }^{14}$. Incluso la biografía que escribió sobre su marido, Timoteo Pérez Rubio y sus retratos de jardín, es un compendio de datos autobiográficos de la propia autora. Esta "invasión” ha hecho que Danièle Miglos y los editores de su obra completa la hayan declarado como autobiografía al incluirla en el mismo volumen que Desde el amanecer.

La investigación de Lydia Masanet (1996) sobre Chacel inicia una fructífera tendencia al estudio sobre la importancia de la autobiografía femenina en la literatura española contemporánea, fijando como corpus de referencia el tratamiento de este género en Mercedes Salisachs, Clara Janés, la condesa de Campo Alange y Rosa Chacel. Para el estudio de lo autobiográfico en Chacel toma en consideración su obra más representativa de este género: Desde el amanecer. Autobiografía de los primeros diez años. Con este estudio comparativo y el análisis de las semejanzas y diferencias entre las cuatro autoras, considera demostrada la riqueza de un género injustamente desprestigiado. La originalidad de Chacel con respecto a las demás escritoras estriba en que su autobiografía abarca desde la etapa prenatal, de la que parece tener conocimiento, hasta la formación final de la narradora a los diez años, donde aparece con claridad que ha terminado su proceso cognoscitivo y su desarrollo emocional e intelectual. La explicación de su infancia tiene que ver directamente con el adulto que narra, con la escritora y su visión del mundo y su amor por el lenguaje.

Si nos preguntásemos qué es lo que no hay de autobiográfico en la obra chaceliana seguramente nos quedaríamos con una parte ínfima de su obra, ya que podemos atrevernos a afirmar, con la seguridad, además, de contar con su aprobación, que su obra es un único y extenso libro. Toda su escritura es el resultado del impulso erótico

\footnotetext{
${ }^{14}$ Para profundizar en el aspecto autobiográfico de la obra chaceliana, véase Romera Castillo (1994) y Puertas Moya (2000).
}

que obliga a la artista a sacar a la luz, a través de su arte, su propia interioridad. Cora Requena $(2000)^{15}$ trabajó sobre esta unicidad de la obra chaceliana en la que sus textos están tan relacionados temática y estructuralmente y en la que, personaje tras personaje, estos individuos reproducen de forma inquietante la vida de la propia autora. Concordamos plenamente con su tesis sobre la existencia de un espacio autobiográfico en la obra chaceliana en el que se relacionan vida y obra como parte de un mismo proceso vital.

El reciente trabajo de María del Carmen Expósito Montes (2013), por fortuna, garantiza la actualidad de la investigación sobre Rosa Chacel en nuestro país. Incide de nuevo sobre el tema de la autorreferencialidad; memoria, voluntad y autobiografía son ahora objeto de estudio en un trabajo que no interesa tanto por la originalidad de sus planteamientos, sino por constituir un acercamiento global a la obra chaceliana. Me parece interesante la incorporación de facetas muy poco estudiadas en relación con la escritora, como su relación con el cine y sus trabajos como traductora y desde luego la aportación de documentos cedidos por Clara Janés y que la autora añade en su aparato documental.

Chacel no ha dejado de hablar de sí misma a lo largo de toda su obra, pero el ser una vida tan llena de acontecimientos (exilios y viajes constantes la mantienen en un movimiento continuo a pesar de su constante lamento sobre el inmovilismo y rutina a que la sujetaba precisamente esa condición de exiliada) forzosamente ha producido textos que se han centrado en las motivaciones profundas de ese empeño por la memoria y en las circunstancias concretas de Chacel. Motivada por el ejemplo y la obra de Ortega y Gasset, apunta Ana M. Gómez Pérez (2005), Chacel convirtió la confesión en piedra de toque de su pensamiento, intentando dar respuesta a la pregunta formulada por Ortega, ¿por qué escasean las memorias y más, las confesiones, en la literatura española? Chacel transforma su proyecto autobiográ-

${ }^{15} \mathrm{Mi}$ agradecimiento a Cora Requena por haberme facilitado un ejemplar del trabajo, inédito.

UNED. REI, 4 (2016), pp. 153-194

ISSN 2340-9029 
fico en un proyecto de confesión, para ella "expresión de una última voluntad, un último deseo antes de que el ser humano sea aniquilado por la imposibilidad de comprender la realidad transcendente" (Gómez Pérez, 2005: 101). Esta investigadora indaga en la teoría chaceliana de la confesión, en sus repercusiones autodestructivas, en un trabajo que nos parece, sobre todo, muy necesario para interpretar, por ejemplo, la que quizá sea la obra cumbre de la autora, La Sinrazón, hoy felizmente reeditada (Chacel, 2015). Gómez Pérez indaga en la memoria individual y colectiva de la literatura española a través de las figuras de Chacel, Baroja, Galdós y Torrente Ballester, en busca de lo que ella denomina signos apocalípticos de la modernidad. Me parece el suyo un acercamiento no solo original, sino muy efectivo. Su método persigue buscar en la memoria - lo que Walter Benjamin llamó el salto del tigre- los signos apocalípticos que surgen de la imposibilidad de crear un cosmos ordenado para el individuo. Este salto al pasado, a la historia, abriría la posibilidad de una redención mesiánica. Con este salto al pasado, siempre posible en la literatura, los escritores analizados tratan de resolver el problema de su "yo" auténtico (y por extensión el de la historia) a través de su destrucción y de su posterior intento de reconstrucción. Tras su minucioso recorrido por la obra de los cuatro autores, Ana Gómez concluye que "Rosa Chacel representa el ejemplo más extremo que puede tomar la modernidad en su búsqueda del tiempo perdido". Es cierto que su caso es diferente al de los demás porque se trata de una mujer que tuvo que hacerse un espacio en varios exilios, pero fundamentalmente dos, el que sufrió por la guerra civil y el exilio del orbe masculino. Rosa Chacel fue rotunda a la hora de negar estas dos situaciones. En el caso del exilio sexual podríamos retrotraernos al comienzo de su obra, pues ya allí encontramos ese empeño de negación sistemática de cualquier indicio de separación o diferenciación sexual, afirmando que el hombre incluye tanto al varón como a la mujer. De esta manera, Chacel se autoinvitaría a una cultura a la que de otro modo no hubiera podido acceder. Asimismo, cuando regresó a España negó constantemente su condición de exiliada y es en estas contradicciones donde Ana M. Gómez encuentra los signos apocalípticos que serán luego recogidos en su poética de la confesión. En este tema precisamente la autora ve ocasión de superar al maestro, puesto que si para Ortega el género de las memorias se relaciona con algo placentero, Chacel le corrige al defender una confesión basada en la culpa que provoca la búsqueda de la comprensión del individuo. En palabras de la autora, la "confesión resucita cadáveres de la memoria en el presente hasta otorgarle un instinto de muerte" (Gomez Pérez 1997: 175); el salto del tigre en el pasado personal despierta chispas mesiánicas portadoras de la autodestrucción.

Jaslenn Kohli (2004) centra su estudio en la memoria transatlántica en la obra de Rosario Castellanos, Rosa Chacel, Brianda Domecq y Soledad Puértolas. Le interesa abordar el espacio biográfico en dos generaciones de escritoras de España y Méjico en las que encuentra una alta conciencia común de mujeres que se expresan por ser personalidades fuertes y resueltas.

Por su parte, Isabel Foncea Hierro (1999) representa la continuidad del interés del estudio de la autora en nuestro país a través del análisis de la obra con la que Chacel había cosechado su primer gran reconocimiento, Barrio de Maravillas (Foncea, 1997), por la que había recibido el Premio de la Crítica en 1976. En este lamentable tardío reconocimiento de Chacel en España hay que situar el origen de las causas de su olvido también por la crítica española, pues si bien ya en 1986 aparece el trabajo de Ana Rodríguez, no serán muchos los trabajos de investigación españoles centrados en la obra de Chacel en estos años.

La novela de formación, ya de larga tradición literaria, se ha conformado como un género cuyo tema central es la representación literaria de las experiencias de un joven protagonista desde su niñez o adolescencia hasta su madurez, en un proceso de aprendizaje que evidencia el conflicto entre sus deseos y los intereses contrarios de la sociedad. El modelo clásico del bildungsroman femenino, de nuevo, se nos aparece como un marco exótico en el que es difícil encajar a su respectivo homólogo femenino, pues es precisamente en el período de formación cuando la niña, la adolescente, está sometida a un 
marco normativo social y familiar mucho más rígido y, en todo caso, absolutamente diferente al del sujeto masculino. La obra chaceliana se ha mostrado como un fértil campo de estudio para la investigación sobre la existencia y las particularidades de este género en nuestra literatura, puesto que Chacel y sus personajes - ya hemos demostrado la indiscutible interdependencia entre vida y otra de la autora- son seres rebeldes que siempre han reflejado el conflicto entre sus deseos y los intereses contrarios de la sociedad. Sus personajes, fundamentalmente Leticia Valle, a la que se ha aludido en este trabajo como paradigmático en absolutamente todas las obras que centran su estudio en este género, representan a la perfección lo que puede ser un modelo de bildungsroman femenino en contraposición al modelo tradicional. Michele Davila Gonçalves (1997) a través de un estudio comparativo de las obras de este género en Rosa Chacel, Rosa Montero, Rosario Castellanos y Elena Poniatowska justifica la aparición tardía de este género precisamente en el hecho de que el desarrollo y formación de las heroínas era muy limitado debido a la situación particular de marginalidad de la mujer. Será precisamente esa situación crítica de las heroínas la característica común que observa en todos los personajes, ya que todas comparten una misma necesidad, la de recordar su pasado. Esta necesidad de activar su memoria les ayudaría a recordar las condiciones sociales, familiares e históricas que propiciaron la imprescindible reevaluación del pasado de las protagonistas y su autoconocimiento. La autora destaca como hecho diferencial, con respecto a sus homólogos masculinos, que cada una encuentra su voz por medio de la escritura, lo que facilita los finales abiertos que insinúan una oportunidad de llenar espacios, con lo que esto significa de esperanza de crecimiento y cambio, a diferencia de los protagonistas masculinos, cuyo final era casi siempre el casamiento, la locura o la muerte. El personaje que mejor lo refleja es la protagonista de Memorias de Leticia Valle, con un final tan abierto que queda absolutamente en manos de quien lee, a quien Chacel cede toda la responsabilidad en función de la interpretación que haga de la dosis de culpabilidad que le atribuya a la niña en la tragedia. Davila defiende la importancia de este género en la literatura femenina por lo que supone de evaluación del papel de la mujer en una época y en un país cualquiera, ya que constituye una respuesta a la necesidad de explorar los significados que expliquen qué es ser mujer.

Tradicionalmente, además, las niñas como personajes literarios han sido tratadas como símbolos cuyo significado es adjudicado por un adulto o bien como seres en transición que sólo tras su crecimiento pueden adquirir voz propia. Annette Bridges (1999) rebate el discurso canónico de las narraciones occidentales que devalúan el papel de la niña en el género de la novela de formación o bildungsroman. Para restablecer la autoridad de la voz subjetiva de la niña, la autora se vale del punto de vista feminista, del concepto existencialista de libertad y de los estudios postcoloniales a través del análisis de algunas "niñas raras" en cuatro novelas de los años cuarenta, de Carmen Martín Gaite, Carson McCullers, Rosa Chacel y Use Aichinger. Leticia Valle vuelve a ser el personaje ideal para reflexionar sobre la autoridad de la voz de una niña, un personaje doblemente marginado, por su edad y por su sexo, para obtener una visión mucho más original y enriquecedora de los procesos en los que se enmarca su narración. Olga Bezhanova (2008) también considera que en la trayectoria del género del bildungsroman femenino en el siglo XX es muy relevante el personaje de Leticia Valle como punto medio entre la novela de aprendizaje tradicional y las tendencias contemporáneas que se producen en este género. Esta posición que otorga a la novela chaceliana se justificaría por un conjunto de diferencias significativas entre el personaje de Chacel y el resto de los personajes de Concha Espina, Carmen Laforet y Ana María Matute que son objeto de su estudio, destacando la fuerte presencia que el sistema patriarcal de dominación ejerce sobre la vida de Leticia y, sobre todo, el hecho de que ella se niega a reconocer el derecho de los demás para imponer su voluntad sobre ella. A pesar de la derrota final que reconoce la niña - en la interpretación de la autora - nunca llegó a internalizar los valores de la sociedad patriarcal que la rodea, y esa falta de control sobre su existencia la compensa creando un espacio textual en el que se alza con una voz propia. Carlos Javier Vadillo Buenfil (2012), en su estudio sobre este género en las narradoras españolas de posguerra,

UNED. REI, 4 (2016), pp. 153-194

ISSN 2340-9029 
a pesar de no incluir un apartado específico para Chacel, no puede obviar tampoco la relevancia de Leticia Valle para aclarar numerosos aspectos de su investigación. Finalmente, la investigación de Aranzazu Sumalla Benito (2012), dirigida por la mejor especialista en la obra chaceliana, Ana Rodríguez Fischer, viene a corroborar la contundente presencia y actualidad de este género en nuestra literatura teniendo muy presente la imprescindible obra de Chacel.

Si tenemos en cuenta que para Chacel su vida y su obra son la misma cosa y que su vida transcurrió casi cuarenta años en el exilio, resulta evidente que esta circunstancia a la fuerza tuvo que dejar profundísima huella en su obra. El exilio provoca en la escritora una sensación de fracaso. Su abatimiento, del que quedaron constantes testimonios en sus diarios, se reforzaba, además, por una situación económica acuciante, pero sobre todo por el sentimiento de soledad que, a pesar de su aversión a la vida social, la hacía aferrarse a cualquier posibilidad de contacto intelectual, como lo demuestra la ingente correspondencia ${ }^{16}$ que mantuvo.

Ame Cividanes (2000) indaga sobre esta extraña circunstancia en la obra de Rosa Chacel, María Teresa León y Mercé Rodoreda. Todas comparten situaciones personales y profesionales arduas como consecuencia de sus más de treinta años de exilio. En su estudio examina las múltiples formas de exilio, que transciende lo que tiene de desplazamiento geográfico para explorarlo en su totalidad, atendiendo a todos los factores culturales, psicológicos y lingüísticos. El exilio funciona, además, como metáfora alusiva a la situación de la mujer escritora como desplazada, como lo "otro". A diferencia de los

${ }^{16}$ El mejor ejemplo por su intensidad es la que mantuvo con Ana María Moix. Una parte de su correspondencia está editada, pero la mayoría se encuentra todavía inédita y custodiada en el archivo de la Fundación Jorge Guillén. Desde aquí manifestamos la urgente necesidad de editar este material, porque constituye, como el resto de la obra de Chacel, un corpus literario imprescindible para tener una visión completa de su obra. El fondo epistolar que se conserva en el Archivo de la Fundación Jorge Guillén es una mínima parte de la correspondencia que mantuvo Chacel en su larga vida. Según Carmen Morán, gran parte de este fondo fue destruido por la autora para evitar su consulta por los "husmeadores de vidas ajenas" (Morán, 2015). escritores exiliados, las escritoras no presentan su singular situación en relación con la política ni con la historia española de esa época, sino que expresan las convicciones y sentimientos que les provoca vivir exiliadas. Desde este punto de vista destaca la representación del espacio y del tiempo en la escritura de todas ellas como factores de alienación y enclaustramiento, situación que no se revierte con su regreso, porque en este momento también se ven obligadas a evaluar de nuevo su identidad en su encuentro con el nuevo pero viejo espacio. Chacel representa a la perfección esta situación de la mujer exiliada cuya angustia persiste con su regreso a España por la reiterada soledad literaria que seguía padeciendo, ahora al comprobar que sus obras no se entendían en el país.

Raquel Conde Peñalosa (2001) en su estudio sobre la producción novelística de las mujeres de la posguerra española y la importancia de la literatura realizada en el exilio, se sorprende ante la paradójica relevancia de la obra de Rosa Chacel en las décadas de los cuarenta y cincuenta frente a la lamentable inexistencia de referencias a la autora en las revistas culturales de la época y su omisión en las principales obras literarias, incluso las que trataban específicamente de escritores exiliados. Ella misma aclara que a punto estuvo de no poder incluirla en su investigación por falta de datos sobre ella. La obra chaceliana, al tener que hacerse valer no en el espacio histórico en el que nace, sino con más de veinte años de demora, supuso una anomalía que extrañamente Conde Peñalosa no juzga negativamente, pues asegura que la producción de Rosa, por demasiado intelectual, no se hubiera entendido ni en los años cuarenta, cuando en nuestro país únicamente se leía literatura rosa, ni en los cincuenta, en los que la hubieran calificado de esteticista. Por supuesto, en los sesenta tampoco se entendió si observamos los pobres y escasos comentarios que su obra suscitaba entre la crítica. Sólo en los setenta se la pudo leer, según ella, como la escritora vanguardista que era y pudieron apreciarse en nuestro país como novedosas las técnicas que la autora había puesto en práctica veinte años antes. No me parece una afirmación descabellada si tenemos en cuenta que su éxito en los setenta no 
fue producto precisamente de una promoción editorial potente, ni por supuesto era la suya una obra de consumo fácil. Según la investigadora, fue la excelencia de su propia obra la que comenzó a despertar el interés de los estudiosos de la literatura, especialmente de las investigadoras. Peñalosa advierte de la necesidad de una relectura de la obra chaceliana porque ocurre con muchas de sus obras lo que con Teresa, por ejemplo, novela que, sin ser feminista, aborda los grandes problemas humanos desde puntos de vista y experiencias feministas.

María del Mar Inestrillas (2002) recupera la temática del exilio para estudiar la posición de autoridad de María Zambrano, Teresa León y Rosa Chacel frente a los discursos establecidos por los contrarios a la República, ya que son obras que promueven la verdad, la libertad y la solidaridad individual frente a la represión ideológica y la anulación de la historia impuesta por la dictadura franquista. Inestrillas se centra en el estudio de los diarios íntimos, que recorren los cuarenta años de la vida de Chacel fuera de España y en los que se destaca la constante metáfora de la náusea con que la escritora expresa su sentimiento de repulsión y asco frente a las condiciones de vida en el exilio y el sufrimiento que le aniquila toda posibilidad de acción, sólo superado por su irrefrenable impulso a la creación literaria.

Beatriz Barrantes-Martín (2005) trata de la proyección de la ciudad en la prosa española vanguardista. Me parece un tema que aún tiene que dar mucho más de sí, porque es una verdad irrefutable que el tema de la mujer ocupó a Chacel desde sus principios (recordemos la conferencia del Ateneo sobre "La mujer y sus posibilidades") y este tema ella siempre lo trató en intimísima relación con el profundo cambio que significaba el nuevo modo de vida que se desarrollaba gracias a las nuevas posibilidades que introducía el desarrollo urbano. En este mismo sentido, se hace necesario recordar aquel flamante ensayo de 1931 en donde la autora reflexionaba en profundidad en la idea de que la cuestión de la mujer — su integración en la vida urbana, así como su relación con el hombre- determina el grado de modernización de un país. La investigación de Barrantes pone el foco en un aspecto que hasta el momento había pasado inadvertido y cuya rele- vancia lleva a la autora a calificar a Chacel de vanguardista integral. El tema es además muy sugerente por lo que tiene de transversal en la obra chaceliana, porque, si la ciudad es un componente, diría incluso que un personaje en novelas como Estación. Ida y vuelta, es también el marco espacial que promueve las reflexiones ensayísticas más interesantes de Chacel. Fue a través del ensayo como nuestra escritora, junto con otras olvidadas intelectuales del momento, lograron canalizar su voz y se incluyeron en el proyecto común del grupo de pensadores dedicados a poner en marcha el necesario proyecto modernizador del país. En esta línea, la aportación de la investigadora en el análisis conjunto de los dos fenómenos me parece lo más atractivo y relevante de su investigación.

La cuestión del apoyo de Rosa Chacel a la lucha antifascista se presenta como problemática por la ausencia de investigaciones rigurosas. Allison Taillot (2013) en su trabajo sobre las intelectuales europeas y la guerra de España contribuye a aclarar esta cuestión. Taillot considera que la defensa de la República Española durante la Guerra Civil constituyó un catalizador para la movilización de las mujeres en favor de un régimen que reconoce sus derechos en la Constitución de 1931. En el contexto de esta investigación en torno al compromiso contra el fascismo de dieciséis mujeres y su participación en la defensa de la cultura, se destaca el compromiso de Rosa Chacel. Nos parece una aportación interesante porque pensamos que también falta en nuestro país una investigación solvente sobre la implicación directa de intelectuales como Chacel con la defensa de la República; como también falta un estudio sobre la guerra fría cultural, al estilo del trabajo de Frances Stonors, (2002) que permita conocer la existencia o no de relaciones de las actividades de los intelectuales españoles con la política cultural promocionada por Estados Unidos. A esto contribuiría una mayor disponibilidad de la documentación personal, correspondencia, sobre todo, de los archivos de escritores que todavía permanecen inéditos.

A la iluminación del trabajo poético de Rosa Chacel, eclipsado por su brillante contribución a la novelística, dedica su investiga- 
ción María Domenica Pieropan (1996), en el que estudia la voz lírica de Chacel y la imagen visual como depositaria de la verdad. Destaca esta autora la renovación que realiza Chacel del soneto a través de imágenes surrealistas, aunque, según Mangini (1996), la utilización de una forma y lenguajes clásicos en su poesía la distanció radicalmente de sus coetáneos. Además, su poesía tampoco se vio favorecida por la rigurosa autocensura que aplicó a su trabajo poético, según explicó ella misma. Sus Versos prohibidos, escritos en los años treinta y cuarenta, fueron publicados sólo en $1978^{17}$. De la calidad poética de nuestra escritora tampoco dudaba lo más mínimo Valle Inclán ${ }^{18}$.

La totalidad de la obra de Chacel es consecuencia de la inquebrantable fuerza de su eros creador, como ella misma ha reconocido en multitud de ocasiones. En este sentido, el trabajo de Susana Báez Ayala (2007) ${ }^{19}$ tiene el atractivo de lo necesario e incluso diría de lo urgente. El estudio que aborda esta investigadora mejicana sobre la memoria vital y la escritura erótica en la narrativa de Rosa Chacel se centra en una faceta de su obra que tiene todavía un largo recorrido, porque es necesario comprender la complejidad de lo que este impulso genésico significa para entender todo el alcance del erotismo en la obra chaceliana.

A pesar del optimismo que sugiere la variedad y rigurosidad de los trabajos aquí reseñados, tenemos que lamentarnos todavía de las imperdonables lagunas que en algunas investigaciones delatan la persistente marginación de Chacel. Puede servir de ejemplo el trabajo de Nieves Gómez Álvarez (2014) sobre el concepto de mujer en la obra del filósofo Julián Marías, para nuestra sorpresa, intelectualmente tan desolador por unas conclusiones con las que nos es totalmente impo-

\footnotetext{
${ }^{17}$ Shirley Mangini (1996: 198) en su estudio de las vanguardias y el discurso del deseo apunta que lo que Chacel prohíbe, implícitamente, es la expresión del deseo.

${ }^{18}$ En un relato que nos deja Chacel sobre una jornada con Valle, dice: "Me dijo que mis versos eran insoportablemente correctos, y que por ese camino de la perfección no daría un paso" (Chacel, 1993b: 451). El interesante juicio de Valle apuntaría a que el excesivo gusto por lo clásico y por la perfección formal entrarían en contradicción con las novedades que incorporaba la estética vanguardista en la poesía.

${ }_{19}$ Tesis doctoral inédita. Agradezco a su autora haberla puesto a mi disposición.
}

sible identificarnos. Consciente de la profunda y declarada amistad que mantuvieron Marías y Chacel, era prácticamente imposible que un buen trabajo sobre el filósofo no aportase información relevante también sobre nuestra escritora. Además, esa sincera y profunda relación en lo intelectual originó un importantísimo corpus documental no sólo en lo privado, a través de su correspondencia, sino públicamente a través de reseñas de sus libros, prólogos o incluso ensayos de uno sobre el otro. Pero lamentablemente Rosa Chacel sólo es mencionada como prueba de la importancia de las amistades femeninas que mantuvo el filósofo en su vida y que coadyuvarían en el diseño de su pensamiento sobre la mujer, además de ser un ejemplo de la generosidad de Marías al destacar su enorme esfuerzo por generar interés por la obra de Chacel. No es cuestión de negar ninguna de estas dos aseveraciones, sino incluso de resaltarlas, pero si algo habría que destacar sobre Chacel en una investigación sobre la mujer en la obra del filósofo, más que los aspectos personales sería su ensayo Comentario a un libro histórico. La mujer en el siglo XX, en el que Chacel introduce importantísimas reflexiones sobre el tema de la mujer en un diálogo muy fructífero con el filósofo. Tenemos que dejar constancia de que después del recorrido por la investigación sobre Chacel que acabamos de hacer nos causa desazón la articulación de un discurso sobre la mujer apoyado en presupuestos filosóficos que ya en 1931 Rosa Chacel empezó a desmentir. Pero lamentablemente a Chacel no se la leyó, ni bien ni mal, y el discurso sobre la mujer, aún teniendo la veta más productiva en nuestro entorno tuvo que importar discursos foráneos.

\section{Conclusiones}

Afortunadamente, el ocultamiento al que en España se condenó a las "pioneras" ya desde el mismo origen del feminismo está siendo revertido gracias a exitosas iniciativas en el ámbito de la difusión ${ }^{20}$ que constituyen el mejor ejemplo de la imperiosa necesidad

20 Es de destacar la gran proyección que está consiguiendo el interesante y multidisciplinar proyecto Las sinsombrero (http://www.lassinsombrero.com).

UNED. REI, 4 (2016), pp. 153-194

ISSN 2340-9029 
de abordar cambios metodológicos si queremos realmente visibilizar y recuperar las obra de mujeres que, como Chacel, construyeron los primeros discursos sobre la mujer en los que sólo su voluntad inquebrantable pudo con la resistencia a la articulación de unos textos en los que cada palabra tenía que ser colocada como si fuese un enorme bloque de piedra en un solar ajeno.

El caso de la autora que nos ocupa es paradigmático por la angustia que sufrió durante toda su vida como consecuencia de un olvido del que se lamentaba continuamente y que la hacía aferrarse a cada posibilidad que surgía de dar a conocer su obra:

Ahora no temo que mis cosas queden arrinconadas y perdidas porque, desde que me cuento entre los cerebros rescatados, es seguro que habrá jóvenes que preparen tesis, etc. Pero todavía es más curioso que yo adoro a esos jóvenes, y que la idea de que hagan sus tesis me causa una satisfacción inmensa (Chacel, 2004:578)

El abundante corpus de tesis doctorales que han tomado como tema la obra chaceliana, aquí descrito, confirma sobradamente la profecía de una autora que reconocía, con motivo de su implacable autocrítica de su ensayo Saturnal:

Hoy día hay bastantes mujeres capaces de hacer su tesis doctoral impecable [...] el defecto evidente de mi libro [...] no puedo darle el grado de abstracción que quisiera la autora, que jamás hizo una tesis doctoral y que se abalanzó sobre la cultura al abordaje ${ }^{21}$.

Con este trabajo intenté, si no paliar la angustia de la autora, cosa que ya no es posible, sí la que nos produce la escasa lectura de su obra a pesar de la riqueza y profusión de los trabajos de "esas jóvenes que prepararon sus tesis" en los últimos años y que han venido a confirmar la insustituible obra de Rosa Chacel.

${ }^{21}$ Notas mecanografiadas para una conferencia encargada a Chacel por Carmen Bozzano, delegada de la Asociación para la Evaluación y Promoción Cultural (APEC). Documento inédito consultado en el Archivo de la Fundación Jorge Guillén.
A lo largo de las páginas de este artículo espero haber demostrado ese riquísimo mundo de posibilidades que ofrece la lectura de la obra chaceliana, pues, si bien el tema de la mujer podemos considerarlo transversal a toda su obra, hay otros muchos que suscitaron el interés de la investigación. Los más profusamente estudiados son lógicamente aquellos que también preocuparon a la autora: la memoria, el exilio, la relevancia de lo autobiográfico en la literatura, las relaciones con Ortega, su asimilación de las propuestas literarias más innovadoras del momento a través de las nuevas posibilidades que para la novela aportaría la narrativa de Joyce y sobre todo las constantes reinterpretaciones de su obra a través de la teoría feminista. Pero también hay aspectos insuficientemente tratados que aguardan tesis y estudios: sobre su faceta filosófica ${ }^{22}$, sus reflexiones teóricas sobre la traducción ${ }^{23}$, su aportación al campo de la historia cultural sobre temas tan variados como el cine, la literatura, la música, el arte ${ }^{24}$ e incluso la violencia de género ${ }^{25}$. Otro tema insuficientemente tra-

${ }^{22}$ Félix Pardo (2001) trata de dilucidar los motivos que han llevado a la crítica literaria a omitir el contenido filosófico de su obra y Roberta Johnson (1997: 267) considera a Chacel, junto con Salinas y Jarnés, como un grupo de novelistas filosóficos en la línea de Joyce, por ejemplo. Chacel reconoció el contenido filosófico de sus novelas una y otra vez. Sobre Estacón. Ida y Vuelta declaró: “...yo hice en esta novela con Ortega, lo que Sartre en La náusea con Heidegger. Es sencillamente un hombre que vive una filosofía". (Mangini, 1989: 27)

${ }^{23}$ Para el análisis de la labor de Chacel como traductora disponemos no sólo de sus reflexiones teóricas, fundamentalmente su artículo "Fedra en español" (Chacel, 1993a: 199), o las numerosas entradas de sus Diarios (2004), sino también de los artículos de Soledad González Ródenas (2001) y Miguel Olmos (2013-14), entre otros.

${ }^{24}$ La formación como escultora de Chacel y su pasión por la forma y la belleza se reflejan en toda su obra a través del imperativo ekfrástico, es decir, el deseo de suspender la temporalidad de la literatura mediante la introducción de los efectos espaciales que ofrecen las artes plásticas (Fernández-Klohe, 2004: 194).

${ }^{25}$ Según Chacel, la sumisión de la mujer se debe a que sabe que es vulnerable, sabe, de forma incluso instintiva, que su anatomía permite ser invadida en contra de su voluntad. Para protegerse de ese miedo ancestral a la violencia de género no encuentra otro camino que el de solicitar protección del hombre, al que, como consecuencia, cede su voluntad. Por otra parte, en numerosas ocasiones, la posibilidad de la mujer de mentir en cuanto a la paternidad contribuiría también a su esclavización 
tado y cuyo interés reclama una investigación rigurosa es el de sus reflexiones sobre la homosexualidad, teniendo en cuenta lo avanzado de sus propuestas en una fecha tan temprana en la que hablar siquiera del mismo, y más siendo una mujer, constituía algo más que una provocación, y que, sin embargo, también ha sido lamentablemente olvidado en la historia del pensamiento de nuestro país ${ }^{26}$. Los textos de Chacel son extraordinariamente valiosos y sugerentes aún a día de hoy por la finura y el rigor de sus reflexiones; y la rotunda originalidad de algunas de sus conclusiones en este terreno (ella hablaba de homoespiritualidad, no de homosexualidad) constituye un hito en el que la investigación, afortunadamente ya iniciada (Morán, 2010), debe avanzar mucho más.

La cantidad de investigaciones nos hace reflexionar sobre la paradoja entre el desconocimiento y la marginación que sufre todavía su obra en el ámbito de la lectura en comparación con el interés que suscita en el ámbito de la investigación. Podemos constatar que este fenómeno ya comenzó a producirse en vida de la autora, puesto que ella misma manifestó en multitud de ocasiones (como en casi todo, ella siempre manifestaba su opinión tajante) la desazón que le producía la escasa atención que suscitaban sus obras. En toda su obra, ensayos, diarios, artículos, conferencias y entrevistas su lamento es constante debido a una marginación de la que se siente culpable.

En lo que respecta a la difusión, es palmario que su nombre nunca ocupó un lugar destacado ni se mantuvo por mucho tiempo en los escaparates de nuestras librerías, menos aún desde que el sector del libro sufre una inflación que obliga a un movimiento de vértigo que imposibilita que casi ninguna obra que no permita prever un absoluto éxito editorial pueda permanecer más de unas horas a la venta. Pedro Quiñonero lo resaltaba con claridad en una entrevista:

(Documento inédito del Archivo Rosa Chacel, signatura RCH13/027).

${ }^{26}$ Nos referimos al ensayo "Esquema de los problemas prácticos y actuales del amor", que ya hemos mencionado aquí y sobre todo a Saturnal.
Los libros genuinos están siendo sepultados por una literatura libresca. Cuando le preguntan si lo peor de nuestros vicios tiene su origen en la picaresca responde que en el siglo XX, Juan Ramón, Ortega, Ramón, Rosa Chacel, en castellano o Pla y Rodoreda, en catalán, aspiran a construir una España más limpia, más noble, menos cutre ${ }^{27}$.

Así que podemos concluir este análisis manifestando el doble sentimiento que nos produce esta situación. Satisfacción, por una parte, al ver el enorme éxito que suscita su obra en los textos académicos, pero desilusión por la perniciosa e imperdonable persistencia en el tiempo de esta anómala situación de ocultamiento de una figura de primer orden no solo para la literatura, sino para el pensamiento en general, pues no olvidemos que la obra de Rosa Chacel es casi un único libro donde ficción y realidad están al servicio de la interpretación del mundo.

La disminución de trabajos posteriores a 2010 es síntoma de la inquietante marginación de una obra que no nos podemos permitir por más tiempo.

Recibido: 8/07/2016

Aceptado: 10/10/2016

\section{Referencias bibliográficas}

Báez Ayala, Susana Leticia (2007), Memoria vial y escritura erótica, origen en la narrativa de Rosa Chacel, Tesis doctoral, Universidad Nacional Autónoma de México.

Barrantes-Martin, Beatriz (2005), Proyecciones de la urbe moderna en la prosa española de vanguardia, Tesis doctoral, Arizona State University. http://search.proquest.com/docview/305026302? accountid=17261 [consulta 15/6/2016].

${ }^{27}$ Declaraciones de Pedro Quiñonero en $A B C$, 31.12.2009. http://www.abc.es/ hemeroteca/historico-31-12-2009/abc/Cultura/los-libros-genuinos-estan-siendosepultados-por-basura-libresca_1132812624026.html [consulta 15/06/2016]

UNED. REI, 4 (2016), pp. 153-194

ISSN 2340-9029 
Bezhanova, Olga (2008), The female bildungsroman in twentieth-century spain: The trajectory of the genre. Tesis doctoral, Yale University. http://search.proquest.com/docview/304423658?accountid=17261 [consulta 15/06/2016].

Birulés, Fina (2015), Entreactos. En torno a la política, el feminismo y el pensamiento, Barcelona: Katz.

Bridges, Annette (1999), What mignon knows: Girlhood subjectivity in three novels of the 1940's, Tesis doctoral, University of Oregon. http:// search.proquest.com/docview/304518343? accountid=17261 [consulta $15 / 06 / 2016]$.

Carvalho, Nilma Machado (2009), A memória da solidão e do tédio nas personagens femininas da obra: Memórias de Letícia Valle de Rosa Chacel, Dissertação, Universidade Federal de Mato Grosso. http:// www.ufmt.br/ufmt/unidade/userfiles/publicacoes/ba50204c3fdd62da46f8e1d4734ec62b.pdf [consulta 14/06/2016]

Chacel, Rosa (1989), Obra Completa, 2. Ensayo y poesía, Valladolid: Editora Provincial, Centro de Creación y Estudios Jorge Guillén, Diputación de Valladolid.

- (1993a), Obra Completa, 3. Artículos I, Valladolid: Fundación Jorge Guillén, Diputación de Valladolid, Centro de Estudios Literarios.

- (1993b), Obra Completa, 4. Artículos II, Valladolid: Fundación Jorge Guillén, Diputación de Valladolid, Centro de Estudios Literarios.

- (2004), Obra Completa, 9. Diarios, Valladolid: Fundación Jorge Guillén, Junta de Castilla y León, Ayuntamiento de Valladolid, Diputación de Valladolid y Universidad de Valladolid.

- (2015), La sinrazón, prólogo de Julián Marías, Barcelona: Comba.

- Fondo documental de la autora en la Fundación Jorge Guillén. Signaturas: RCH09/001-153, RCH10 /001-126, RCH11 /001-109, RCH12 /001-066, RCH13 /001-063, RCH14 /001-138, RCH15 /001085, RCH16 /001-057.

Cividanes, Anne M. (2000), El exilio interior-exterior en la obra de Rosa Chacel, María Teresa León y Mercé Rodoreda, Tesis doctoral, The
Florida State University. http://search.proquest.com/docview/304591060? accountid=17261 [consulta 15/06/2016]

Conde Peñalosa, Raquel (2001), The Spanish post-war women's novel (1940-1960): Sociological approach and bio -bibliographical, Tesis doctoral, Universidad de Deusto. http://search.proquest.com/docview/3 04791360? accountid=17261 [consulta 15/6/2016].

Davila Gonçalves, Michele (1997), El archivo de la memoria: La novela de formación femenina de Rosa Chacel, Rosa Montero, Rosario Castellanos y Elena Poniatowska, Tesis doctoral, University of Colorado. http://search.proquest.com/docview/304359747?accountid=17261 [consulta $15 / 06 / 2016]$.

Expósito Montes, María del Carmen (2013), Escritura autorreferencial en Rosa Chacel, Tesis doctoral, Universidad de Jaén. http://ruja.ujaen. es/bitstream/10953/457/1/9788484397298.pdf [consulta 15/06/2016]

Fernández Utrera, María Soledad (1995), Visiones de estereoscopio. paradigma de integración en la ficción y el arte de la vanguardia espanola, Tesis doctoral, University of Southern California. http://search. proquest.com/docview/1648430920? accountid=17261 [consulta $15 / 6 / 2016]$

Fernandez-Klohe, Carmen (2004), "Motivos iconográficos en la novelística de Rosa Chacel", en Isaías Lerner, Robert Nival y Alejandro Alonso eds., Actas del XIV Congreso de la Asociación Internacional de Hispanistas: New York, 16-21 de Julio de 2001, Newark: Juan de la Cuesta, vol. 3, pp.193-199.

Foncea Hierro, Isabel (1997), La interrelación simbólica en la obra de Rosa Chacel: Barrio de Maravillas, clave interpretativa, Tesis doctoral, Universidad de Málaga.

- (1999), Rosa Chacel: memoria e imaginación de un tiempo enigmático, Málaga: Centro Cultural Generación del 27.

Gajic, Tatiana (2001), In search of a lost nation: Intelectual Genealogies and Historical Revisions of the Reform of the Spanish Nation in José Ortega y Gasset, María Zambrano y Rosa Chacel, Tesis doctoral, 
Duke University. http://search.proquest.com/docview/250853625?account $\mathrm{id}=17261$ [consulta 17/6/2016].

Gómez Álvarez, Nieves (2014), Mujer: persona femenina. Un acercamiento mediante la obra de Julián Marías, Tesis doctoral, Universidad Complutense de Madrid. http://eprints.sim.ucm.es/25435/. [consulta 15/6/2016].

Gómez Pérez, Ana María (1997), Las trampas de la memoria. pensamiento apocalíptico en la literatura española moderna: Galdós, Baroja, Chacel y Torrente Ballester, Tesis doctoral, Universidad de Pensilvania, http://search.proquest.com/docview/1626311088? accountid=17261. [consulta 12/6/2016].

- (2005), Las trampas de la memoria. pensamiento apocalíptico en la literatura española moderna: Galdós, Baroja, Chacel y Torrente Ballester, Newark: Juan de la Cuesta.

- (2014), "La nueva Ifigenia: feminismo, vanguardia y exilio en $L a$ Sinrazón, de Rosa Chacel”, Crítica Hispánica, XXXVI, 1, pp. 19-33.

González Ródenas, Soledad (2001), “Rosa Chacel: creación, traducción y crítica. A propósito de seis tragedias de Racine”, en Francisco Lafarga y Antonio Domínguez coords., Los clásicos franceses en la España del siglo XX: estudios de traducción y recepción, Barcelona: PPU, pp. 99-106.

Grau-Llevería, Elena (1997), Cuestionamiento histórico y propuestas feministas en escritoras hispanoamericanas y españolas contemporáneas, Tesis doctoral, Universidad de Texas. http://search.proquest.com/ docview/304391489? accountid=17261 [consulta 15/6/2016].

Inestrillas, María del Mar (2002), Exilio, memoria y autorrepresentación: La escritura autobiográfica de María zambrano, María Teresa León y Rosa Chacel, Tesis doctoral, Ohio State University. http:// search.proquest.com/docview/305500905? accountid=17261 [consulta 15/6/2016].

Johnson, Roberta (1997), Fuego cruzado. Filosofía y novela en España (1900-1934), Madrid: Libertarias/Prodhufi.
Kennedy, Teresa (1995), A translation of Rosa Chacel's Estación, ida y vuelta with an introductory essay, Tesis doctoral, California State University. http://search.proquest.com/docview/304279211 ?accountid=17261 [consulta 15/6/2016].

Kohli, Jasleen (2004), Una memoria transatlántica: La narrativa autobiográfica de Rosa Chacel, Rosario Castellanos, Brianda Domecq y Soledad Puértolas, Tesis doctoral, Universidad de California, Riverside. http://search.proquest.com/docview/305203777? accountid=17261 [consulta $15 / 6 / 2016]$.

Lázaro Gurtubay, Reyes (1995), Indecisiones y seducciones familiares: Rosa Chacel, Ortega y la generación del noventayocho, Tesis doctoral, University of Massachusetts. http://search.proquest.com/docview/30411 1810 ? accountid=17261 [consulta 17/6/2016]

- (2002), “Cartografía de la 'intro-versión'. Rosa Chacel a la luz de Judith Butler", en Raquel Medina y Barbara Zecchi eds., Sexualidad y escritura (1850-2000), Barcelona: Anthropos, pp. 181-192.

León-Blázquez, Lidia (2011), Telarañas: Rosa Chacel y la narrativa femenina de la vanguardia española, Tesis doctoral, Stony Brook University. http://search.proquest.com/docview/874964439?accountid=17261 [consulta 17/6/2016].

Lind, Julie Mann (2013), From hungers to appetites: Women writers after the Spanish Civil War, Tesis doctoral, Cornell University. http:// search.proquest.com/docview/1466014369? accountid=17261 [consulta 17/6/2016].

Mangini, Shirley (1989), "Introducción”, en Chacel, Rosa, Estación. Ida y vuelta, Madrid: Cátedra.

- (1996), "Las vanguardias y el discurso del deseo”, en Iris M. Zavala coord., Breve historia feminista de la literatura española (en lengua castellana). III La mujer en la literatura española. Modos de representación desde el siglo XVIII a la actualidad, Barcelona: Anthropos, pp. 177-212.

- (2006), "Rosa Chacel, el feminismo en la obra de una antifeminista”, en Pilar Celma Valero y Carmen Morán Rodríguez eds., Con 
voz propia: la mujer en la literatura española de los siglos XIX y XX, Burgos: Fundación Instituto Castellano y Leonés de la Lengua, pp. $165-178$.

Mari Pegrum, Annalisa, ed. (2015), Beat Attitude. Antología de mujeres poetas de la generación beat, Madrid: Bartleby Editores.

Martínez-Carbajo, María A. (2001), Eros y pandora: La novelística de rosa chacel y el mundo de la circunstancia orteguiana, Tesis doctoral, University of Washington. http://search.proquest.com/docview/2507 85425 ? accountid=17261 [consulta 15/6/2016].

Masanet, Lydia (1996), La autobiografia femenina contemporánea en España, Tesis doctoral, University of Southern California. http:// search.proquest.com/docview/304294668? accountid=17261. [consulta $15 / 6 / 2016]$.

Miglos, Daniéle (1990), Rosa Chacel et l'usage de la parole, Tesis Doctoral, Université Charles de Gaulle, Lille.

Morán Rodríguez, Carmen (2006), 'Homo Sapiens'. La formación de la conciencia del sujeto literario en la obra de Rosa Chacel, Tesis doctoral, Universidad de Valladolid.

- (2010), "El eros homosexual en el pensamiento de Rosa Chacel", en Alfonso Ceballos Muñoz y Candela Delgado Marín coords., Soy lo que ves. Cultura, identidad y representación homosexual, Madrid: Septem Ediciones, pp. 213-227. https://www.academia.edu/19294994/_El_eros_ homosexual_en_el_pensamiento_de_Rosa_Chacel [consulta 17/6/2016].

- (2015), "Algunas calas en los materiales poéticos del archivo de Rosa Chacel", Revista de la Asociación Internacional para el Estudio de Manuscritos Hispánicos, 1, pp. 35-60.

Nylén, Sofia Iaffa (2014), Prosamodernism, form och genusdebatt. En komparativ form-och receptionsstudie av Karin Boyes Astarte och Rosa Chacels "Estación. Ida y vuelta", Tesis doctoral, Sockholms Universitet. http://www.diva-portal.se/smash/get/diva2:733881/FULLTEXT02.pdf [consulta 24/6/2014]
Olmos, Miguel (2013-14), “Traducciones de Hérodidade: la versión de Rosa Chacel en Ciclón (1957)", Travaux et Documents Hispaniques, 5, pp. 35-50 http://eriac.univ-rouen.fr/category/publications/publicationselectroniques/tdh/mallarme-en-traduction-aire-hispanique/ [consulta $10 / 4 / 2016]$.

Pardo, Félix (2001), "Voces pitagóricas en el pensamiento de Rosa Chacel”, Aurora. Papeles del Seminario María Zambrano, 3, pp.101114.

Pattison, Lori Beth (1993), Engendering selves: Modes of representation in rosa chacel's first four novels, Tesis doctoral, University of Kansas. http://search.proquest.com/docview/304064713?accountid=17261 [consulta 15/6/2016].

Pieropan, Domenia (1996), Rosa Chacel, "la orilla de un pozo": A study of the sonnets, Tesis doctoral, University of Massachusetts Amherst. http://search.proquest.com/docview/304269798? accountid=17261. [consulta 15/6/2016].

Puertas Moya, Francisco Ernesto (2000), "La condición autobiográfica en Rosa Chacel”, en Marina Villalba Álvarez coord., Mujeres novelistas en el panorama literario del siglo XX: I Congreso de narrativa española, Cuenca: Universidad Castilla-La Mancha, pp. 173-182.

Requena Hidalgo, Cora (2000), La poética de las ideas en la narrativa de Rosa Chacel. La unicidad de un universo poético autobiográfico, Tesis doctoral, Universidad Complutense de Madrid.

- (2002): "La mujer en los textos de Rosa Chacel (1898-1994)", Espéculo, 21, https://dialnet.unirioja.es/servlet/articulo?codigo $=266903$ [consulta $12 / 2 / 2016]$

Risbud, Sheila Marie (1995), Estacion. ida y vuelta: El viaje de Rosa Chacel hacia la "nueva novela" de Ortega, Tesis doctoral, Universidad de Otawa. http://search.proquest.com/docview/304260063?account $\mathrm{id}=17261$. [ consulta 15/6/2016] 
Rodríguez-Fischer, Ana (1986), La obra novelística de Rosa Chacel, Tesis Doctoral, Universitat de Barcelona. http://www.tesisenxarxa.net/ handle/10803/1714 [consulta 15/6/2016].

- (1993), "Introducción" a Rosa Chacel, Barrio de Maravillas, Madrid: Castalia.

- (1998), De mar a mar. Epistolario Rosa Chacel-Ana María Moix, Barcelona: Península.

Romera Castillo, José (1994), "La escritura autobiográfica de mujeres en España (1975-1991)", en Juan Villegas coord.., Actas Irvine-92. Actas de XI Congreso de la Asociación Internacional de Hispanistas, Irvine: University of California, vol. 2, pp. 140-148.

Scarlett, Elizabeth Ann (1991), Spanish women writers and the reconquest of inner space: Gender, the body, and sexuality in novels by Emilia Pardo Bazán, Rosa Chacel, and Mercé Rodoreda, Tesis doctoral, University of Harvard. http://search.proquest.com/docview/303904825?accou ntid=17261 [consulta 15/6/2016].

- (1997): "Retrato de la joven Rosa Chacel", Bazar. Revista de Literatura, 4, pp. 110-117.

Stonor Saunders, Frances (2002), La CIA y la guerra fría cultural, Barcelona: Círculo de Lectores.

Sumalla Benito, Aránzazu (2012), La novela de formación en la narrativa española contemporánea escrita por mujeres, Tesis doctoral, Universitat de Barcelona. http://hdl.handle.net/2445/46328 [consulta 15/06/2016]

Taillot, Allison (2013), "Les intellectuelles européennes et la guerre d'Espagne: De l'engagement personnel à la défense de la république espagnole", Cahiers De Civilisation Espagnole Contemporaine, 11. http://ccec.revues.org/4760 [consulta 15/6/2016]

Vadillo Buenfil, Carlos Javier (2012), El bildungsroman en las narradoras españolas de posguerra: 1940-1960, Tesis doctoral, Universidad Autónoma de Madrid. http://hdl.handle.net/10486/660405 [consulta $15 / 06 / 2016]$ 